\title{
Optimal Design for the Diffusion Plate with Nanoparticles in a Diffusive Solar Cell Window by Mie Scattering Simulation
}

\author{
Ruei-Tang Chen, Chih-Chieh Kang, Jeng-Feng Lin, Tzu-Chi Lin, and Chih-Wen Lai \\ Southern Taiwan University of Technology \& Science, Tainan, Taiwan \\ Correspondence should be addressed to Chih-Chieh Kang; kangc@mail.stust.edu.tw
}

Received 15 September 2013; Accepted 14 October 2013

Academic Editor: Teen-Hang Meen

Copyright (C) 2013 Ruei-Tang Chen et al. This is an open access article distributed under the Creative Commons Attribution License, which permits unrestricted use, distribution, and reproduction in any medium, provided the original work is properly cited.

\begin{abstract}
A diffusive solar cell window comprises a diffusion plate with $\mathrm{TiO}_{2}$ nanoparticles sandwiched between two glass layers. It is a simple, inexpensive, easy-to-made, and highly reliable transparent solar energy module. To improve its power generation efficiency as well as maintain indoor natural lighting, we examined the scattering mechanism in the diffusion plate with $\mathrm{TiO}_{2}$ nanoparticles within a diffusive solar cell window by Mie scattering simulations. In this work, a multiwavelength ASAP ray tracing model for a diffusive solar cell window with acceptable accuracy was developed to investigate the influence of the diffusion plate design parameter, mainly concentration of a diffusion plate with determined particle size distribution, on power generation efficiency and color shift of transmitted sun light. A concept of "effective average radius" was proposed to account for the equivalent scattering effect of a size distribution of quasispherical particles. Simulation results demonstrated that both the transmitted light and its correlated color temperature decreased as the concentration increased for a large-size diffusive solar cell window. However, there existed a maximum power generation efficiency at around $160 \mathrm{ppm}$ concentration. The optimal design for a large-size diffusion plate inside a diffusive solar cell window by taking indoor lighting into account was suggested based on the simulation results.
\end{abstract}

\section{Introduction}

Building integrated photovoltaic (BIPV) is an important application of future solar energy development. The integration of solar cells into windows must not only generate electrical power but also maintain indoor natural lighting. Various types of power generation on windows have been developed by the application of BIPV technology. In most cases, solar cells are directly placed on/in windows [1-7]. But such approach often fails to fulfill one of the basic functions of windows-lighting. Alternatively, solar cells can be placed on the edges of a window. Through depositing a thin film layer of fluorescent molecules on glass, due to internal total reflection of light in glass, a highly efficient solar cell was developed [8]. To further enhance the light guide effect and increase the power generation efficiency as well, a diffusive solar cell window is designed and fabricated with uniformly distributed diffusive nanoparticles in a polycarbonate diffusion plate that is sandwiched between two glass layers [9]. A typical prototype diffusive solar cell window is shown in Figure 1. Its basic structure and main light-transport mechanisms responsible for the enhancement of solar power generation, including multiple scattering inside diffusion plate and total internal reflection at the front and back interfaces between the glass and the air, such as light rays (4), (5), and (7), are illustrated in Figure 2. As a whole, it does exhibit a certain degree of "light-guide" effect. Although, with all its merits, the commercial applications of diffusive solar cell windows are still limited, part of the reason is due to that the contemporary large-size diffusive solar cell windows still do not meet the performance requirement for high power generation efficiency. Since the diffusion plate is the most significant factor influencing power generation efficiency, it is crucial to optimize its design in order to resolve the issue.

Based on Mie theory of light scattering, optical simulations have been widely used to study light transport in diffusion plate, in tissues, in atmosphere, and in environment, and so forth, and have gained some ground in these research areas [10]. To efficiently and effectively improve the power generation performance of a large-size diffusive solar cell window in terms of development time and cost, Mie scattering optical simulation is the best choice for 


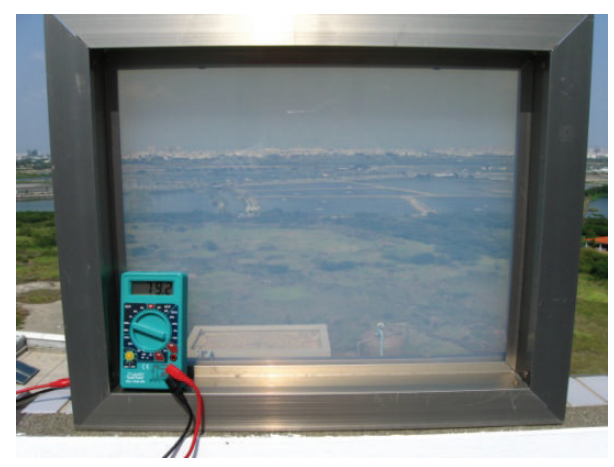

FIGURE 1: A $1 \times 1$ feet diffusive solar cell window prototype at work. Light rays

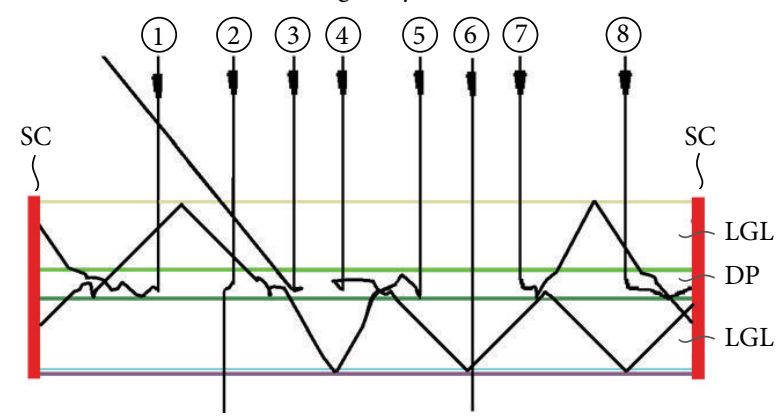

DP: diffusion plate

LGL: light-guide layer (glass)

SC: silicon solar cells

FIGURE 2: Schematic illustration of the basic structure of a diffusive solar cell window as well as various mechanisms of light transport inside.

implementation compared to the more common practiceexperimental approach. In this work, a multiwavelength ray tracing model using Advanced Systems Analysis Program (ASAP) was constructed to examine the optical mechanisms which influence the power generation efficiency of a diffusive solar cell window, especially the optimal design parameters for the diffusion plate with nanoparticles of a large-size diffusive solar cell window by taking both high power generation performance and indoor lighting into account.

\section{Optical Model for a Diffusive Solar Cell Window}

Generally, our devised diffusive solar cell window is made up of a diffusion plate-polycarbonate (PC) plate embedded with titanium dioxide $\left(\mathrm{TiO}_{2}\right)$ nanoparticles which was sandwiched between two glass plates. In practice, ethylene vinyl acetate (EVA) was used to laminate glass and PC. Accordingly, an ASAP ray tracing model was developed to simulate the measurement of a five-layer diffusive solar cell window in a solar simulator with acceptable accuracy. A typical crosssectional dimension of a diffusive solar cell window structure for general purpose building applications implemented in simulations is shown in Figure 3. A rectangular tubular

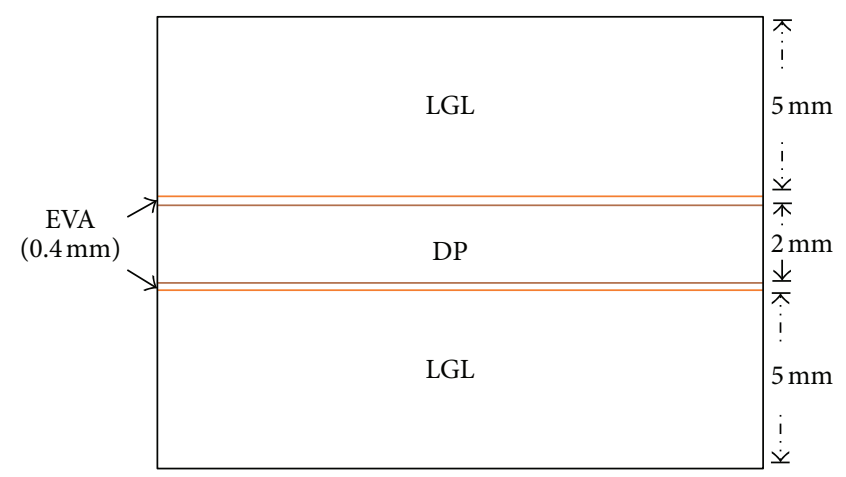

FIGURE 3: The implemented cross-sectional dimension (in proportion) for a typical diffusive solar cell window.

absorption surface was surroundingly positioned in close proximity to the edge of the diffusive solar cell window to act as solar cells in simulations. Another absorption surface was placed proximately behind the back interface of the diffusive solar cell window, which was between the glass and the air, to track down all of the transmitted light.

\section{Optical Simulations}

The optical simulations were divided into two main steps: (i) the construction of an accurate wavelength-dependent diffusion plate optical model and (ii) optimal design for a diffusive solar cell window.

In order to corroborate the five-layer diffusive solar cell window model, a prior work - the construction of an accurate wavelength-dependent optical model for the diffusion plate-was performed since the diffusion plate is the key component in a diffusive solar cell window. By simulating the transmittance spectra measurement of the diffusion plate using a spectrophotometer, a simplified ASAP model of transmittance spectra measurement for the diffusion plates with different concentrations of $\mathrm{TiO}_{2}$ nanoparticle was constructed. It consisted of a diffusion plate, a variable singlewavelength slit light source, and a detection surface that served as the entrance port opening of an integrating sphere. The densities of $\mathrm{TiO}_{2}$ and PC were assumed to be $4.0 \mathrm{~g} / \mathrm{cm}^{3}$ and $1.2 \mathrm{~g} / \mathrm{cm}^{3}$, respectively. Given a radius of a nanoparticle, different concentrations of nanoparticle in a diffusion plate can be determined in simulations.

By Mie scattering theory, the aggregate of $\mathrm{TiO}_{2}$ nanoparticles in a diffusion plate was assumed to be spherical, isotropic, and uniform in size. In fact, there was a size distribution of around $200 \sim 300 \mathrm{~nm}$ for $\mathrm{TiO}_{2}$ nanoparticles implemented in this work, as shown in Figure 4. Therefore, we proposed a concept of "effective average radius" to approximate the average radius of an aggregate of nanoparticles which took the equivalent scattering effect of a size distribution of quasispherical particles into account. Different "effective average radii" within the range of $\mathrm{TiO}_{2}$ nanoparticle size distribution were tested in the simulations of diffusion plate transmittance spectra measurement. The simulation results then were compared to the experimental measurements not 


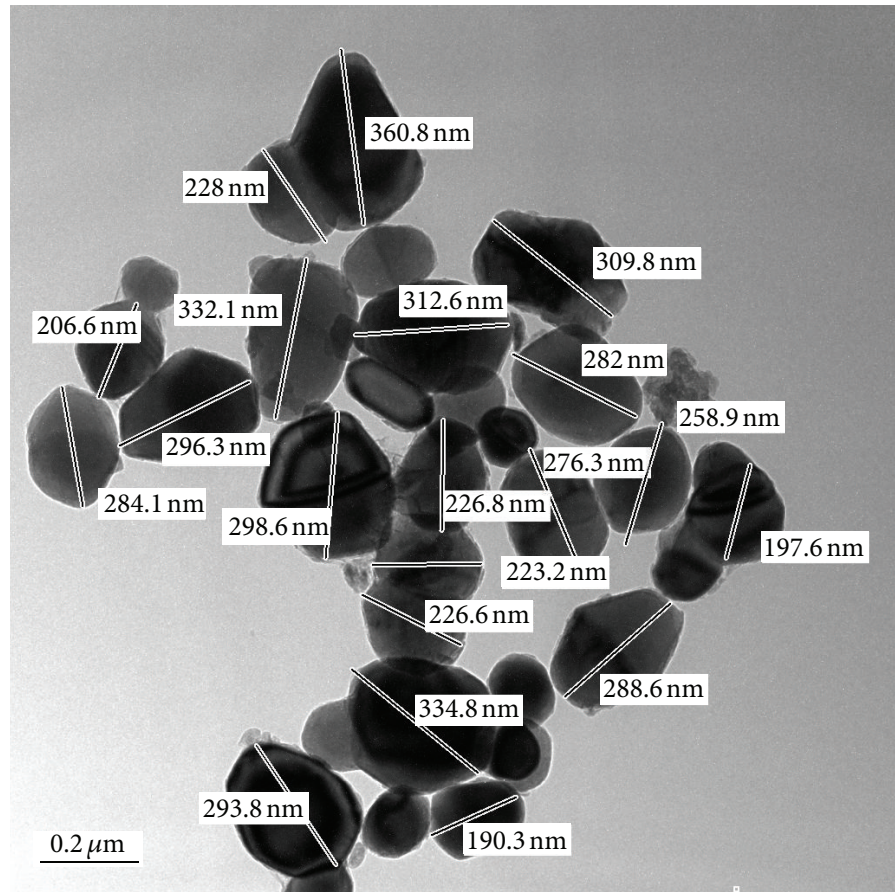

FIGURE 4: TEM image of the $\mathrm{TiO}_{2}$ nanoparticle aggregates.

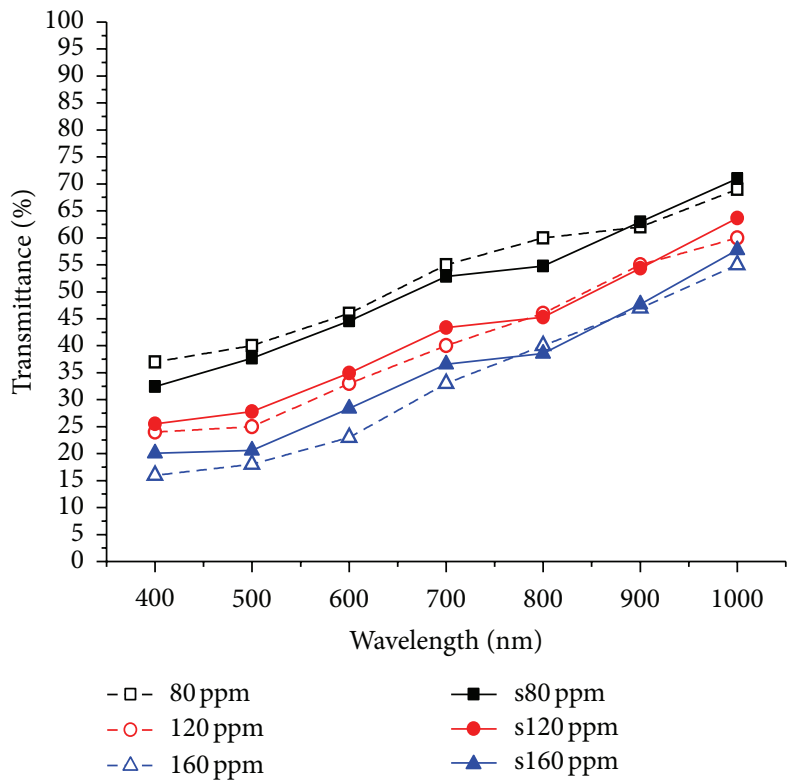

FIGURE 5: Comparison of transmittance spectra of a diffusion plate with $\mathrm{TiO}_{2}$ nanoparticles between simulation and experiment. Solid line (-): simulation. Dash line (- - - ): experiment.

only to validate the accuracy of the wavelength-dependent diffusion plate model but also to determine the operating "effective average radius" implemented in the diffusive solar cell window model. With resort to dynamic light scattering (DLS) measurements for the aggregate of $\mathrm{TiO}_{2}$ nanoparticles [11], the validity of operating "effective average radius" was examined.

As for the refractive indices $(n)$ and extinction coefficients $(\kappa)$ of glass, EVA, $\mathrm{TiO}_{2}$, and PC, they do vary with wavelength in the solar spectrum for silicon solar cell which is approximately from 400 to $1150 \mathrm{~nm}$ [12], whereas the extinction coefficients of glass, EVA, and PC are so insignificant that they were assumed to be zero for most optics applications. Since there exists multiple scattering inside the diffusion plate and "light-guide" effect along the glass plates, the propagation loss of light transport in a diffusive solar cell window cannot be ignored any more; that is, their extinction coefficients cannot be assumed to be zero. In this work, the extinction coefficients of glass, EVA, and PC were determined based on the measured transmittance spectra of blank glass, EVA, and PC by a spectrophotometer which were then converted to extinction coefficients through corresponding transmittance spectra simulations. More particularly, the measured transmittance spectra of a $2 \mathrm{~mm}$ thick blank PC plate were served as a baseline in the transmittance spectra simulations for a diffusion plate.

In the second step, there were two feasible approaches to perform the simulations for optimizing a diffusive solar cell window design by assigning the light source of the diffusive solar cell window model either to be one single operating wavelength or to be multiwavelength. Though singlewavelength approach could provide valuable information to improve the design of a diffusive solar cell window, but a more accurate model was needed in order to optimize its performance. Therefore, the multiwavelength approach was adopted in this work. An ASAP multiwavelength five-layer diffusive solar cell window measurement model was then developed. Simulations were performed to determine the power generation, transmittance, and transmitted light color of different-size diffusive solar cell window with given concentrations of $\mathrm{TiO}_{2}$ nanoparticle. The accuracy of this model was verified through the comparison between the simulation results and experimental data. Further simulations were 


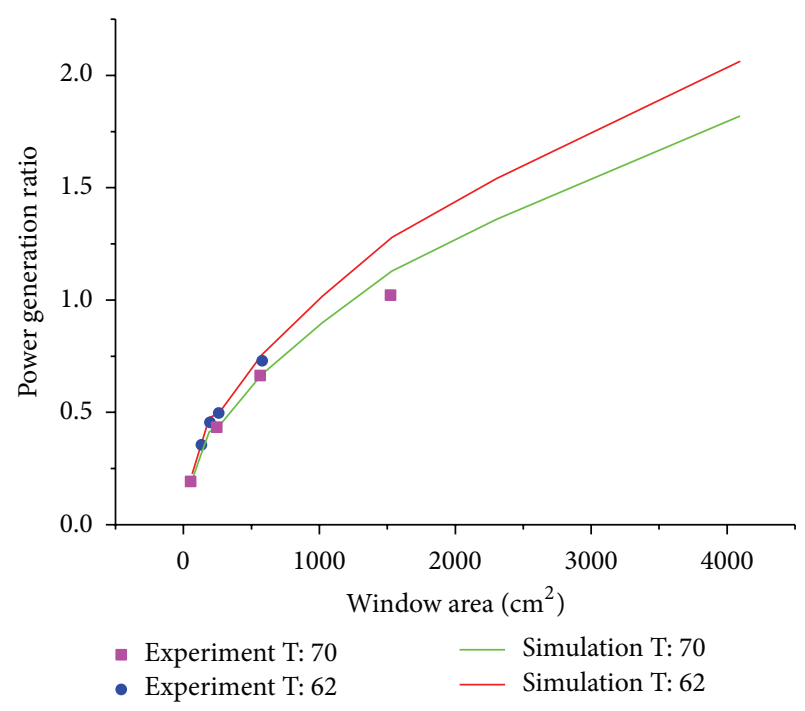

(a)

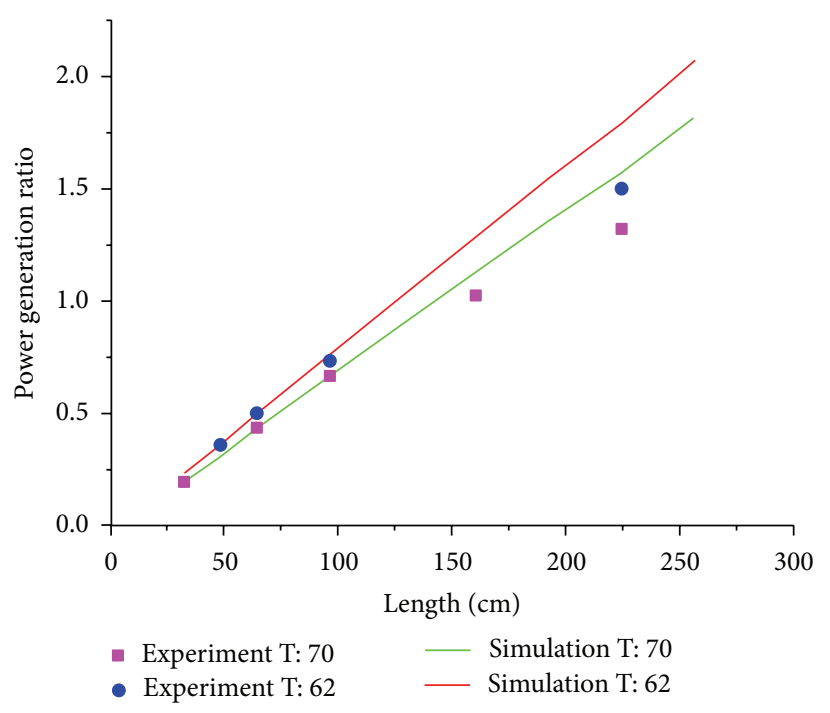

(b)

FIGURE 6: Comparison of power generation ratio of diffusive solar cell windows with different sizes between simulation and experiment in terms of (a) window area and (b) window perimeter.

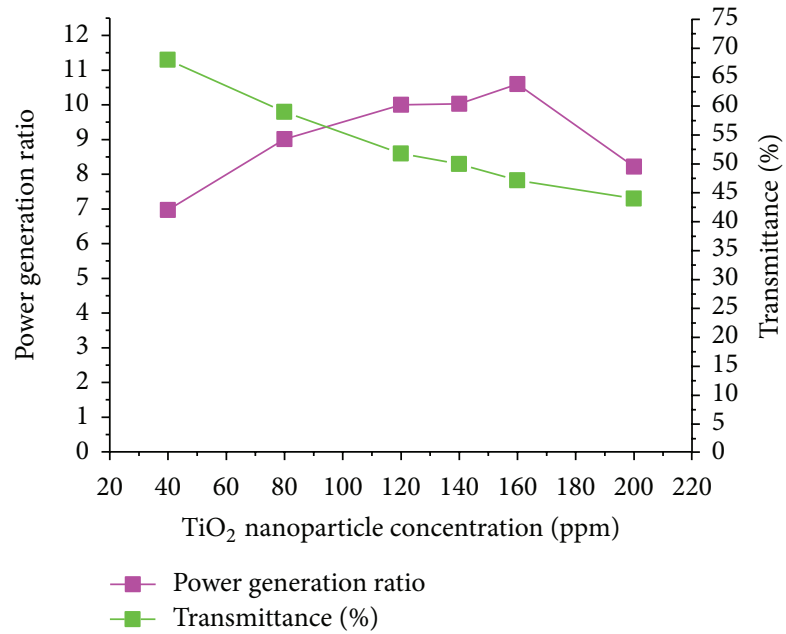

FIGURE 7: Simulation results of power generation ratio and transmittance for a $64 \times 64 \mathrm{~cm}$ diffusive solar cell window with different concentrations of nanoparticle.

performed to attain the optimal design for a large-size 640 $\times 640 \mathrm{~mm}$ diffusive solar cell window.

\section{Simulation Results and Discussion}

In the simulations of transmittance spectra measurements of the diffusion plate with $\mathrm{TiO}_{2}$ nanoparticles, the "effective average radius" of a $\mathrm{TiO}_{2}$ nanoparticle was determined to be $140 \mathrm{~nm}$ by the examination of all of the simulation results and comparison with experimental data. For this case, the transmittance spectra comparison between the simulation and the experiment demonstrated that the constructed diffusion plate model can exhibit acceptable accuracy across the whole silicon solar cell spectrum, as shown in Figure 5. Appreciably and deliberately, higher transmittances occurred in low-wavelength region and lower ones in high-wavelength region. Higher errors appeared at the lower end of the spectrum by our model, since the spectra transmittance of $\mathrm{PC}$ varied significantly in the region of $400 \mathrm{~nm}$.

To validate the accuracy of the developed multiwavelength five-layer diffusive solar cell window measurement, we compared simulation results to the experimental measurements, as shown in Figure 6 . By means of an $8 \times 8 \mathrm{~cm} / 70 \%$-T diffusive solar cell window with a $0.189 \mathrm{~W}$ power generation as a standard of reference, the power generation ratio is defined as the power generation of a test window over the reference value. $70 \%$-T stands for an $80 \mathrm{ppm}$ diffusion plate with $\mathrm{TiO}_{2}$ nanoparticles used, and $62 \%-\mathrm{T}$ is for a $140 \mathrm{ppm}$ one.

In Figure 6(a), it shows that the power generation ratio does not increase linearly with window size (amount of incident simulated sun light); it gradually saturates as the window area increases. In Figure 6(b), the power generation ratio variation versus window perimeter also exhibits the same trend; it saturates as window size becomes greater. Besides, the generation power ratio is greater if the window parameter is larger based on the same window size.

For future commercial applications, a $64 \times 64 \mathrm{~cm}$ diffusive solar cell window, which was near a $2 \times 2 \mathrm{ft}$ size window, was simulated. The simulation results are shown in Figure 7. It demonstrated that the transmitted light decreased as expected as the particle concentration increased from $40 \mathrm{ppm}$ to $200 \mathrm{ppm}$. However, the power generation ratio did not increase with increasing particle concentration. There existed a maximum power generation ratio at around $160 \mathrm{ppm}$ concentration. It suggested that the optimal design parameter for particle concentration was around $100 \mathrm{ppm}$, based on the tradeoff between power generation ratio and 


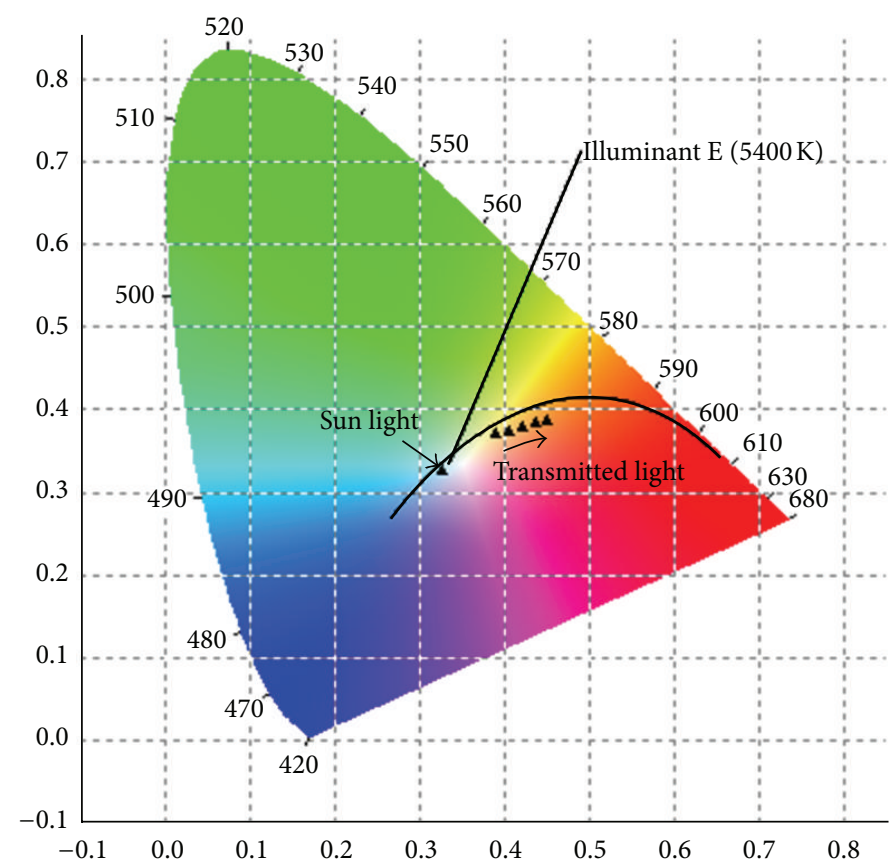

FIGURE 8: Simulation results of correlated color temperature variation of transmitted light for a $64 \times 64 \mathrm{~cm}$ diffusive solar cell window with the increment of nanoparticle concentration.

light transmittance. The correlated color temperature of the transmitted light decreased as the particle concentration increased as expected, as shown in Figure 8. Since the light was absorbed and scattered in a PC diffusion plate with nanoparticles in a diffusive solar cell window at around $400 \mathrm{~nm}$.

\section{Conclusions}

We have developed an ASAP optical multiwavelength model for a diffusive solar cell window with acceptable accuracy which can be used to optimize the design for a large-size diffusive solar cell window. We also proposed a concept of "effective average radius" to account for the equivalent scattering effect of a size distribution of quasispherical particles. For a $64 \times 64 \mathrm{~cm}$ diffusive solar cell window, there existed a maximum power generation ratio at around $160 \mathrm{ppm}$ concentration in simulations. It did not increase with increasing particle concentration. The simulation also suggested that particle concentration of about $100 \mathrm{ppm}$ was the optimal design parameter, given determined "effective average radius" of $140 \mathrm{~nm}$, by taking indoor natural lighting into account. Its light transmittance can still maintain above $50 \%$.

\section{Conflict of Interests}

The authors ensure that there was no conflict of interests in this study.

\section{Acknowledgments}

This work was in part supported by the National Science Council (Grant no. NSC 102-2221-E-218-021) and by the Ministry of Economic Affairs (Grant no. 102-E0603), China.

\section{References}

[1] A. Takeoka, S. Kouzuma, H. Tanaka et al., "Development and application of see-through a-Si solar cells," Solar Energy Materials and Solar Cells, vol. 29, no. 3, pp. 243-252, 1993.

[2] M. Biancardo, K. Taira, N. Kogo et al., "Characterization of microspherical semi-transparent solar cells and modules," Solar Energy, vol. 81, no. 6, pp. 711-716, 2007.

[3] A. Goetzberger and V. Wittwer, "Fluorescent planar collectorconcentrators: a review," Solar Cells, vol. 4, no. 1, pp. 3-23, 1981.

[4] T. Miyazaki, A. Akisawa, and T. Kashiwagi, "Energy savings of office buildings by the use of semi-transparent solar cells for windows," Renewable Energy, vol. 30, no. 3, pp. 281-304, 2005.

[5] W. He, Y. X. Zhang, W. Sun, J. X. Hou, Q. Y. Jiang, and J. Ji, "Experimental and numerical investigation on the performance of amorphous silicon photovoltaics window in East China," Building and Environment, vol. 46, no. 2, pp. 363-369, 2011.

[6] Y. F. Chiang, R. T. Chen, A. Burke, U. Bach, and P. Chen, "Noncolor distortion for visible light transmitted tandem solid state," Renewable Energy, vol. 59, pp. 136-140, 2013.

[7] J. G. Kang, J. H. Kim, and J. T. Kim, "Performance evaluation of DSC windows for buildings," International Journal of Photoenergy, vol. 2013, Article ID 472086, 6 pages, 2013.

[8] M. J. Currie, J. K. Mapel, T. D. Heidel, S. Goffri, and M. A. Baldo, "High-efficiency organic solar concentrators for photovoltaics," Science, vol. 321, no. 5886, pp. 226-228, 2008.

[9] R.-T. Chen, J. L. H. Chau, and G. L. Hwang, "Design and fabrication of diffusive solar cell window," Renewable Energy, vol. 40, no. 1, pp. 24-28, 2012.

[10] W. Hergert and T. Wriedt, Eds., The Mie Theory, Springer, New York, NY, USA, 2011.

[11] A. Colombo, F. Tassone, F. Santolini, N. Contiello, A. Gambirosio, and R. Simonutti, "Nanoparticle-doped large area PMMA plates with controlled optical diffusion," Journal of Materials Chemistry C, vol. 1, no. 16, pp. 2927-2934, 2013.

[12] http://www.refractiveindex.info. 

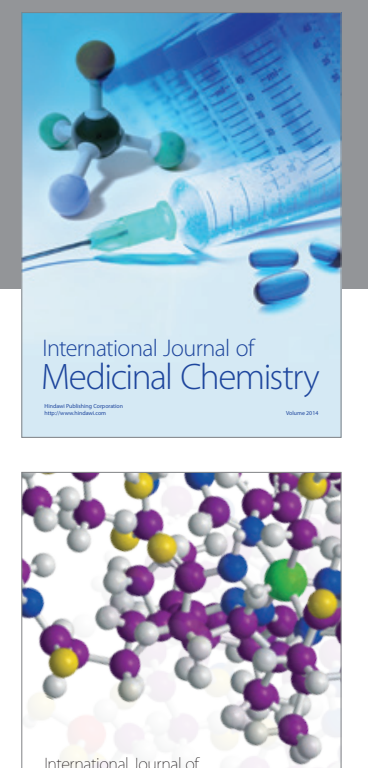

\section{Carbohydrate} Chemistry

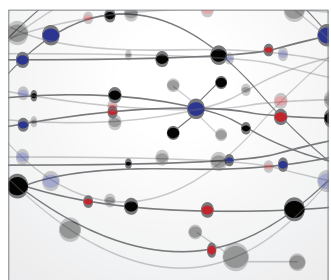

The Scientific World Journal
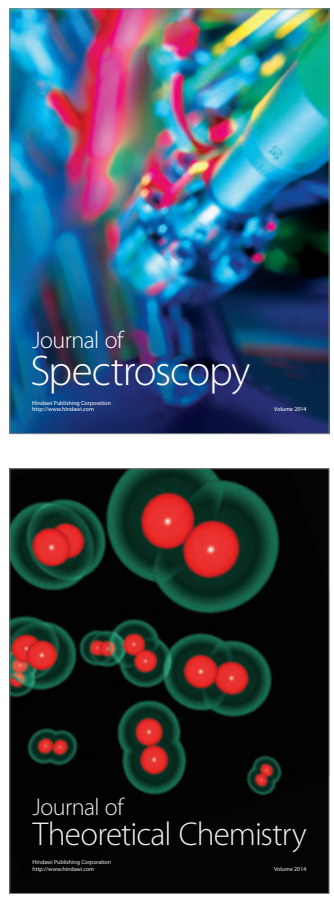
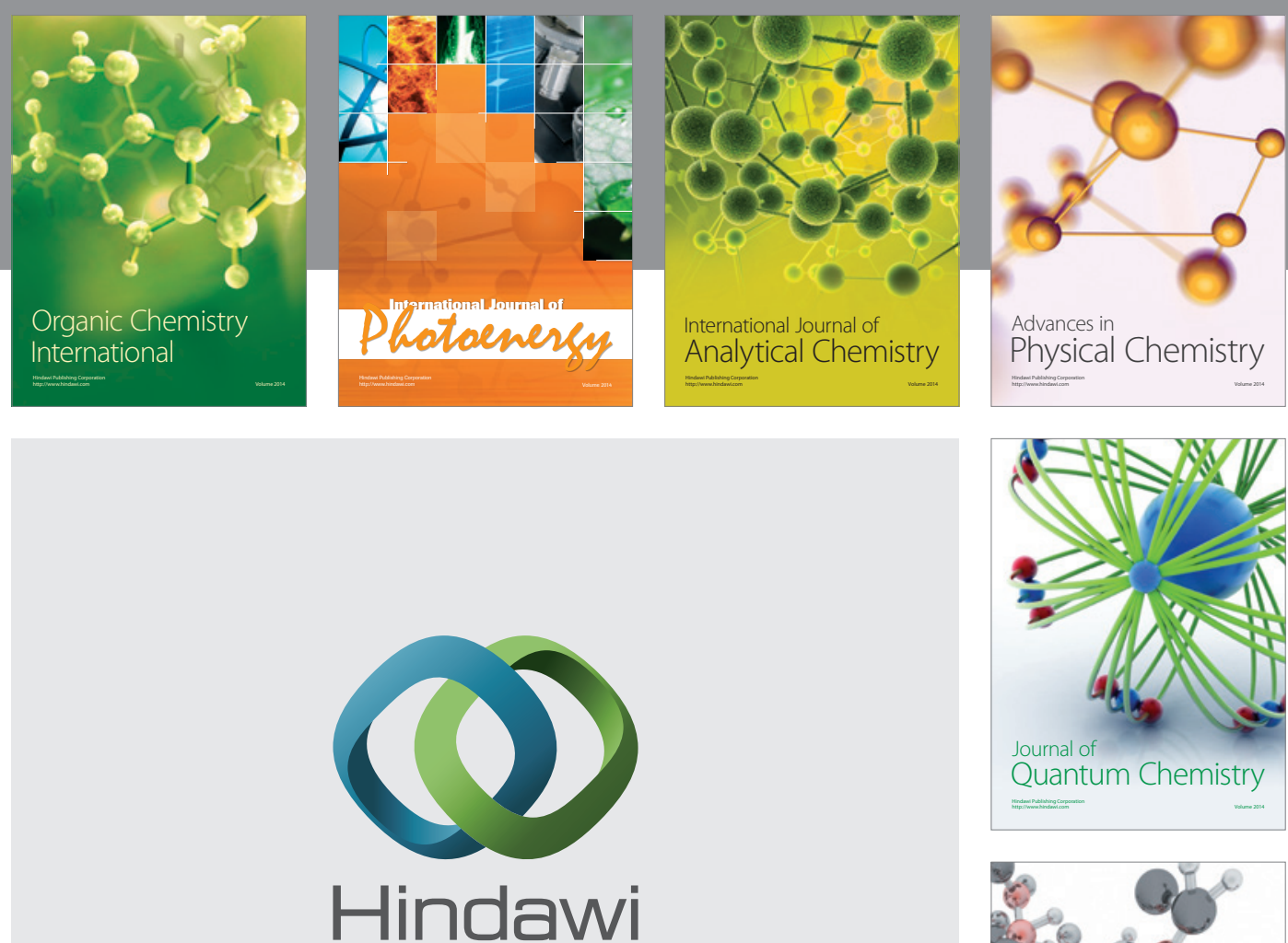

Submit your manuscripts at

http://www.hindawi.com

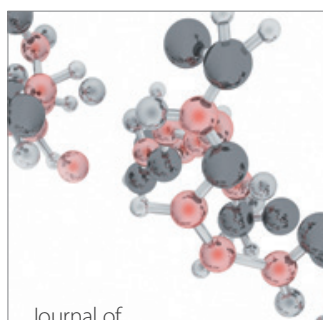

Analytical Methods

in Chemistry

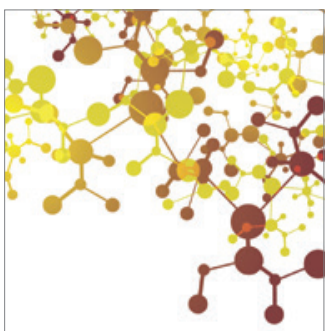

Journal of

Applied Chemistry

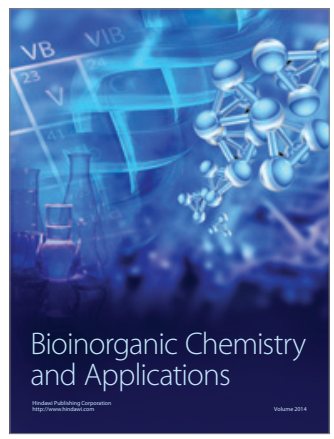

Inorganic Chemistry
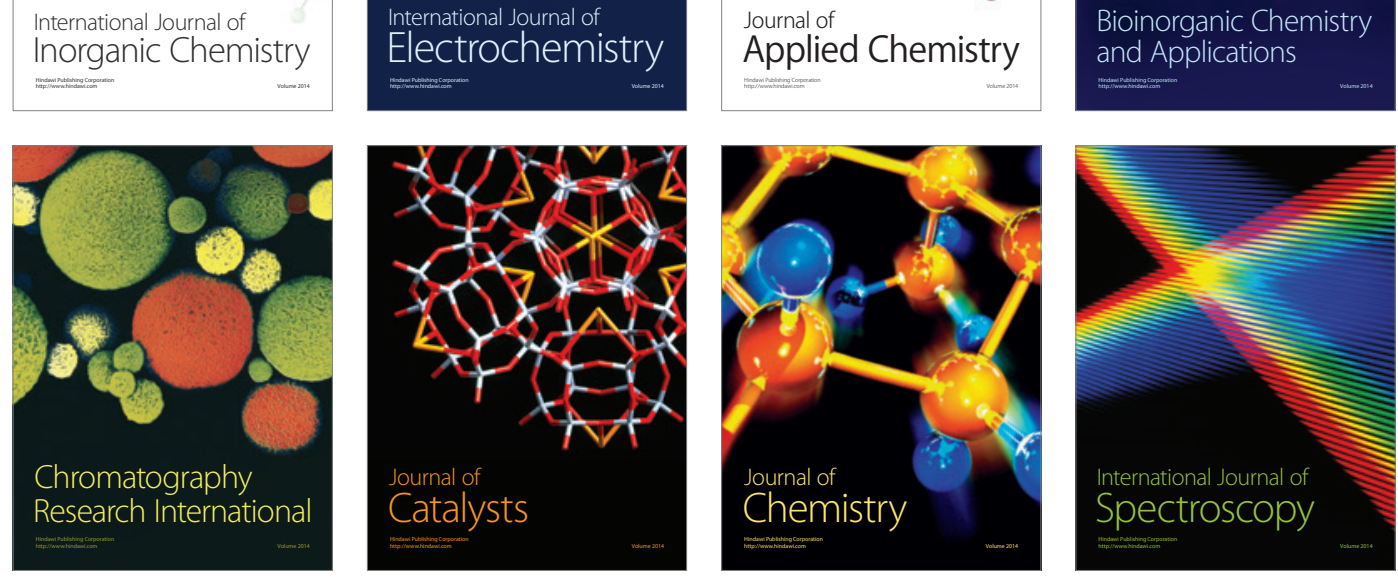